\title{
Arqueologia do Sul do Brasil e política colonial em Hermann von Ihering ${ }^{1}$
}

\author{
Lúcio Menezes Ferreira*
}

\begin{abstract}
A marcha ascendente de nossa cultura está em perigo; é preciso pôr cobro a esta anormalidade que a ameaça. Protejam-se os indios pacificos, mas garantam-se ao mesmo tempo aos colonos a vida e a propriedade contra assaltos de indios bravios.
\end{abstract}

Hermann von Ihering (1911, p.113)

Resumo. Este artigo analisa as pesquisas arqueológicas de Hermann von Ihering em suas relações com a construção de uma política colonial.

Palavras-chave: Arqueologia. Museu Paulista. Sul do Brasil.

Política colonial.

* Mestre e Doutorando em História Cultural pela UNICAMP. Bolsista FAPESP. Núcleo de Estudos Estratégicos/Unicamp.

Anos 90, Porto Alegre, v. 12, n. 21/22, p.415-436, jan./dez. 2005 
Arqueologia do Sul do Brasil e política colonial em Hermann von Ihering

A formação acadêmica de Hermann von Ihering (1850-1930) deu-se em Göettigen, onde ele obteve PhD em Medicina, em 1873, e em Filosofia, em 1876. Tornou-se, em 1878, Privatdozent em Zoologia da Universidade de Leipzig. Partiu para os trópicos em 1880, para trabalhar como naturalista viajante do Museu Nacional, adquirindo em 1882 cidadania brasileira (Losano, 1992). Seus estudos abrangeram diversas áreas da História Natural; porém, dedicou-se principalmente, desde a sua tese de doutorado, à Zoologia e Paleozoologia dos Moluscos, sendo considerado um notável malacologista. A pesquisa que o projetou internacionalmente, em 1907, versou sobre os antigos continentes Archelenis e Archinotis, que lhe permitiram elaborar a teoria das pontes continentais, fundada em seus estudos relativos aos moluscos do sudeste sulamericano.

Suas pesquisas sempre tiveram uma dimensão continental. Ao entronizar-se como Diretor do Museu Paulista, cargo que ocupou por vinte e dois anos (1894-1915), realizou, baseando-se nas coleções angariadas em expedições, por compra e intercâmbio com museus e institutos de pesquisa internacionais, uma série de trabalhos comparativos em História Natural. Como nos mostra Margaret Lopes (1997, p.265-291), von Ihering sempre acalentou o sonho de fundar um museu sul-americano. Daí seus trabalhos comparativos, marcadamente de caráter biogeográfico e zoogeográfico, paleontológicos e geológicos, se acercarem das regiões limítrofes ao Rio da Prata. Aos seus domínios científicos, contudo, von Ihering incluía, também, a Arqueologia. Em suas pesquisas sobre a ciência da cultura material, notam-se as mesmas preocupações comparativas, a mesma ambição científica de produzir sínteses regionais.

A região privilegiada por von Ihering para suas pesquisas comparativas em Arqueologia foi o Sul do Brasil. Mesmo antes de dirigir o Museu Paulista, von Ihering, tendo vivido por alguns anos no Rio Grande do Sul, sobretudo às margens da Lagoa dos Patos 
(von Ihering, 1907a), já publicara, em alemão e inglês, trabalhos arqueológicos sobre o Sul do Brasil. Neles, concebeu uma outra "ponte continental", desta vez não apenas paleogeológica, mas também arqueológica; entre os Andes, as regiões do Rio da Prata e o sul do Brasil, von Ihering circunscreveu uma diáspora de artefatos e de grupos pré-históricos; delimitou um conjunto de relações culturais, cujo ponto limiar seria o Sul do Brasil.

Suas pesquisas arqueológicas foram, sem dúvida, reconhecidas internacionalmente, sendo freqüentemente citadas em perió-

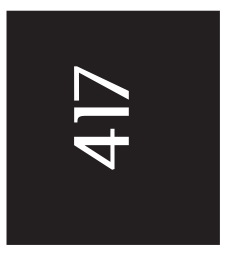
dicos estrangeiros, como por exemplo, na prestigiosa American Anthropologist (Chamberlain, 1912; Haseman, 1912; Saville, 1913). Nesse artigo, contudo, meu objetivo não é só o de avaliar como o diapasão de suas interpretações em Arqueologia se afinava pelos tons da ciência internacional, mas sobretudo, o de mostrar como de suas hipóteses sobre o povoamento pré-histórico do Sul do Brasil deriva um projeto político; suas pesquisas arqueológicas encerram, com efeito, uma política colonial.

\section{O método}

De fato, as pesquisas arqueológicas de von Thering inseriram-se no contexto internacional. Ele tinha convivência crítica com a literatura antropológica, arqueológica e lingüística de sua quadra histórica; de seus textos pululam citações de arqueólogos, antropólogos e lingüistas que lhe foram coetâneos. Estava bem inteirado sobre o discurso acadêmico de seu tempo, especialmente no que diz respeito às teorias científicas de esteio racista, cujas proposições afirmavam o caráter racialmente hereditário da inteligência e do comportamento e explicitavam teses eugênicas, como as de Francis Galton (1822-1911).

Ademais, se se quisesse, facilmente poderíamos enquadrá-lo no modelo histórico-cultural em Arqueologia - modelo que, como 
Arqueologia do Sul do Brasil e política colonial em Hermann von Ihering

se sabe, continua vivo e atuante na Arqueologia contemporânea (cf., por ex., Shennan, 2000). Herdeiro do nacionalismo do século XIX, o modelo histórico-cultural em Arqueologia parte do pressuposto de que cada nação compor-se-ia de um povo, um grupo étnico definido biologicamente, um território delimitado e uma cultura, pensada em termos de língua e tradições sociais. Tais elementos, uma vez isolados em homologias e tipologias, formariam o conceito de cultura arqueológica: um conjunto de artefatos semelhantes, datados num período específico, representantes de um povo, de uma cultura, de um território.

Do mesmo modo, facilmente o classificaríamos como um difusionista. Sua síntese arqueológica do Sul do Brasil, com definição de áreas culturais e migração de povos e artefatos, equiparase às interpretações arqueológicas e etnológicas de Friedrich Ratzel (o qual ele cita) e Franz Boas. Esses modelos, efetivamente, não estão ausentes nos textos de von Ihering; é preciso, entretanto, lêlos também com outras lentes, focá-los sob uma outra perspectiva, atinente ao fundamento espacial de sua epistemologia arqueológica. Em von Ihering, a questão territorial era central. Mais do que constituir identidades no tempo histórico, sem contudo desdenhálo, é na Geografia que von Ihering marca e demarca a etnogênese dos grupos indígenas. Princípio geoestratégico, e não somente histórico - estratégias de ocupação do espaço, das distribuições territoriais, dos deslocamentos regionais, das imigrações de grupos pré-históricos e de artefatos.

Tal fundamento espacial da Arqueologia resulta, em von Ihering, de sua formação como naturalista. Ele participou do movimento que se convencionou designar - mas que é o índice de uma regulação metodológica generalizada - como ciência bumboldtiana. Parafraseando Bruno Latour, Martin Rudwick (2000, p.51), historiador da Paleontologia, recentemente afirmou que, comparadas à vida social dos laboratórios, as ciências de campo são, para a historiografia especializada, terra semi-incógnita. Contu-

Anos 90, Porto Alegre, v. 12, n. 21/22, p.415-436, jan./dez. 2005 
do, ainda assim sabemos, por pesquisas modernas, como as de Michael Dettelbach (1997) e Janet Browne (1997), que a Física da Terra de Alexander von Humboldt (1769-1859) reverteu a História Natural como ciência da coleta. Tornou-a uma nova topografia da terra, ancorada nos exames de precisão de medidas dos modernos instrumentos - o barômetro, o cronômetro, o quadrante, o sextante, o teodolito, o higrômetro, os compassos, as agulhas magnéticas etc.

O uso de métodos gráficos e linhas isométricas serviu para

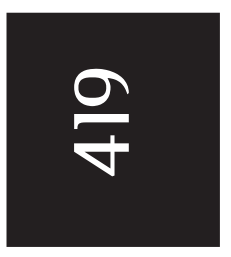
cartografar um largo espectro de variáveis: meios de temperatura, nivelamento e pressão barométrica, proliferando o uso dos mapas para os estudos em História Natural. A Biogeografia, as pesquisas sobre a distribuição geográfica das plantas e animais sobre o globo, tornou-se, ademais, uma taxionomia das diferenças. Fizeramse pesquisas sobre as distribuições geográficas, formularam-se as ontologias identitárias das diferentes regiões, classificaram-se as especificidades da natureza dos continentes. A nova topografia da terra, com seus instrumentos de medida, mapas e métodos aritméticos, lastrou as teorias de distribuição das espécies e a análise do conjunto das coleções. As técnicas numéricas fornecidas pela Estatística e pela Demografia foram largamente utilizadas para contabilizar e definir as "nações" e "províncias" de plantas e animais de uma região.

A metodologia da ciência humboldtiana organiza, de fato, os textos arqueológicos de von Ihering. Acostumado à sistemática, às lides classificatórias das espécies, ele exibe-nos um extremo apuro e perícia na descrição e análise da cultura material indígena. Assim, não somente interpretou as sobrevivências dos artefatos préhistóricos entre os pescadores do litoral paulista e catarinense (von Ihering, 1905, 1907b, p.243-244); realizou também exercícios de Arqueologia experimental, conforme se vê em Os Machados de Pedra dos Índios do Brasil e o seu emprego nas derrubadas de mato (1907c). Inspirando-se nos trabalhos de arqueólogos dinamarqueses, von 
Arqueologia do Sul do Brasil e política colonial em Hermann von Ihering

Ihering, ao lado de Ernesto Garbe (naturalista viajante do Museu Paulista) e Matias Wacket ("colecionador do Alto da Serra"), manuseia, numa mata próxima à caixa de água do Alto da Serra do Mar (SP), machados líticos da coleção do Museu Paulista, visando observar-lhes a eficácia na preparação do solo para a agricultura.

Concluiu pela presteza dos machados; foram eles bem fabricados para o fim a que se destinavam, isto é, a derrubada de árvores de porte médio. Para assim concluir, von Ihering cronometrou as horas de trabalho e, sobretudo, analisou detidamente os machados, num padrão descritivo que conceituo como geometria dos artefatos. Padrão que, na Arqueologia brasileira, inaugura-se a partir dos anos 1870, particularmente nos trabalhos de Charles F. Hartt (1840-1878) (1876a, 1876b). Tratava-se assim, para von Ihering, de conhecer as propriedades, formas, medidas, modelos e funções dos artefatos; tratava-se de pesá-los, medi-los, de descrevê-los recorrendo a metáforas geométricas, de deduzir, a partir da geometria, o cálculo racional dos artefatos, sua precisão tecnológica, esmero estético e funcionalidade.

A essa preocupação com a precisão de medidas e cálculos geométricos corresponde uma outra tarefa; não só uma geometria dos artefatos, mas também uma geografia dos artefatos. Em todos os textos arqueológicos e antropológicos de von Ihering há a análise cartográfica da distribuição territorial, da imigração, das trocas e do comércio dos artefatos. Há também uma imbricação metodológica entre geometria e geografia dos artefatos. Tome-se, por exemplo, o ensaio A Civilização Pré-Histórica do Brasil Meridional (1895), publicado no volume inaugural da Revista do Museu Paulista. Nele, vê-se que ambos os padrões descritivos, uma vez articulados metodologicamente, implicam fazer-se não só uma tipologia dos artefatos, não só interpretá-los em seus significados funcionais e rigor tecnológico, mas também em traçar-se "paralelos etnográficos" (von Ihering, 1895, p.73) e "estudos comparati- 
vos de artefatos análogos" (idem). Com isto, chega-se a uma etnogênese, ao "valor etnológico dos artefatos" (idem).

Fazendo a geometria e geografia dos artefatos, von Ihering isola etnias, inferidas por meio de procedimentos comparativos, busca regularidades culturais, motivos semelhantes, correspondências temáticas - de um modo muito parecido ao que Ginzburg (1989, p.143-180) conceituou como "paradigma indiciário". Há em seus textos uma hermenêutica dos sinais grafados nos artefatos, uma leitura das marcas e emblemas timbrados pela imigração dos grupos pré-históricos, pelas influências culturais externas ou recíprocas. Decifrando esses sinais, von Ihering procura entender "a distribuição geográfica deles sobre o continente sul-americano e as conclusões que permitem a respeito da extensão e imigração dos povos que os fizeram" (von Ihering, 1895, p.150).

\section{O Brasil andino}

Da aplicação desse método surge a síntese de von Ihering sobre a Pré-História do Sul do Brasil. Obviamente, como nunca se escreve sobre páginas em branco, von Ihering teve, atrás de si, os resultados de algumas escavações arqueológicas de sambaquis de Santa Catarina e do Rio Grande do Sul, efetuadas durante o Império pelo Conde de La Hure (1865), Ladislau Neto (1876) e Charles Wiener (1876). Do mesmo modo, von Ihering não foi o primeiro a produzir sínteses de alcance global; Ladislau Neto (18381894), em 1885, já publicara suas Investigações sobre a Arqueologia Brasileira (1885), tentando balizar hipóteses sobre a ocupação préhistórica do Brasil.

Contudo, escrevendo dez anos depois de Ladislau Neto, von Ihering, no ensaio A Civilização Pré-Histórica do Brasil Meridional (1895), compulsou um universo empírico mais alargado do que aquele examinado pelo Diretor do Museu Nacional em suas Investigações.

Anos 90, Porto Alegre, v. 12, n. 21/22, p.415-436, jan./dez. 2005

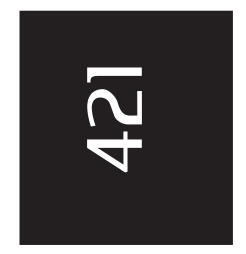


Arqueologia do Sul do Brasil e política colonial em Hermann von Ihering

Além da literatura arqueológico-etnográfica então disponível, ele abarcou as ricas coleções arqueológicas e etnográficas do acervo do Coronel Joaquim Sertório, núcleo original do Museu Paulista, e também aquelas reunidas pelas expedições da Comissão Geográfica e Geológica de São Paulo, dirigida por Orville A. Derby (18541918). Utilizou, ainda, as coleções de outros museus brasileiros, europeus e norte-americanos; aproveitou os freqüentes contatos científicos que mantinha com os diretores de museus argentinos, tais como Francisco P. Moreno (1852-1919), Florentino Ameghino (1853-1911) e Juan B. Ambrosetti (1865-1917), para ampliar suas fontes, literárias e materiais, sobre a Arqueologia do noroeste argentino e das regiões adjacentes ao Rio da Prata. Assim, ele pôde sublinhar com maior nitidez os contornos cartográficos do povoamento pré-histórico do Sul do Brasil. Em seus textos arqueológicos e etnográficos subseqüentes, todos eles de fôlego, von Ihering sempre retomou o ensaio de 1895, reiterando suas hipóteses de imigração e definições de enclaves arqueológico-regionais.

A síntese de von Ihering, em seus traços fundamentais é apresentada na última parte de seu ensaio, dedicada às comparações entre o Rio Grande do Sul, São Paulo e os "Estados do Rio da Prata" (von Ihering, 1895, p.105-155). O argumento principal da comparação é a demonstração empírica da existência de um Brasil andino. Desde o princípio do ensaio, von Ihering anuncia que escreverá uma História comparativa dos materiais arqueológicos do Sul do Brasil. Ou, para ser mais exato, o objetivo de von Ihering é o de abordar comparativamente "tradições históricas" (von Ihering, 1895, p.47-60) - segundo elas se postulam na historiografia, nas crônicas coloniais e relatos de viagens científicas - e "tradições arqueológicas" (von Ihering, 1895, p.60-101) - segundo os registros da cultura material por ele estudados. Assim, von Ihering descreve a diáspora de uma "cultura superior" em solo brasileiro (von Ihering, 1895, p.105-106). 
O Diretor do Museu Paulista rastreia os caminhos por que percorreram os artefatos de influência incaica; mostra que, ao longo dos Andes e em direção ao Norte, nota-se a influência crescente dos Incas, espargindo os seus vestígios por meio de trocas econômicas e culturais, por todas as partes do Rio Grande do Sul e da Argentina, até a embocadura do Amazonas (von Ihering, 1895, p.131). Uma série de vestígios arqueológicos comprovaria, para von Ihering, os contatos dos Incas para além de seu território imediato: o cultivo de plantas muito específicas, como a coca, o mi-

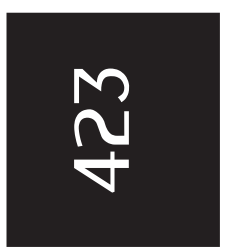
lho, a mandioca, o feijão e o algodão, encontradas na Venezuela, no Paraguai, na Argentina setentrional e no Rio Grande do Sul; os machados de cobre e motivos pictográficos da "arte rupestre" da Argentina setentrional, sobretudo os da cidade de Catamarca, seriam semelhantes aos do Rio Grande do Sul (von Ihering, 1895, p.153-154).

Hermann von Ihering, em seguida, define duas regiões arqueológicas, ou, como ele preferiu dizê-lo, uma síntese de duas "regiões transitórias" (von Ihering, 1895, p.151). Haveria dois territórios arqueológicos de um Brasil andino. De um lado, Catamarca ligar-se-ia à Ilha de Marajó, pois as refinadas urnas funerárias, lá e acolá, apresentariam figurações simbólicas semelhantes. Assim, uma primeira região arqueológica formou-se numa zona de contato entre os grupos incaicos assentados no Noroeste argentino e os habitantes da Ilha de Marajó. As cerâmicas incas, e aqui von Ihering fala hipoteticamente, teriam descido o Amazonas e aportado na Ilha de Marajó, onde se transfiguraram num novo estilo cultural (von Ihering, 1895, p.152). De Catamarca irradiaram também as trocas culturais que originaram algumas tradições arqueológicas Guaranis. O grupo pré-histórico que teria servido de intermediário entre os Guaranis e os Incas seria o dos Calchaquis de Catamarca (von Ihering, 1895, p.126).

Essa segunda "região transitória", no interior das fronteiras do Brasil, formaria um paredão natural, uma esfera isolante, pois a 
Arqueologia do Sul do Brasil e política colonial em Hermann von Ihering

influência andina, propagando-se em "círculos ondulatórios", deparara-se ante as determinações da Geografia Botânica e Zoológica do Rio Grande do Sul (von Ihering, 1895, p.155). O Sul do Brasil, em termos paleontológicos, paleobotânicos, geológicos e arqueológicos, configuraria uma região singular. Aqui, é principalmente o malacologista quem fala: von Ihering, que sempre exultou das ricas coleções de conchas terciárias e pós-terciárias do Museu Paulista (von Ihering, 1898, p.14), classificou os moluscos da Costa da Argentina como similares àquelas do Rio Grande do Sul (von Ihering, 1897). Todo o sul do Brasil formaria um tecido único, natural e arqueológico, a demarcar uma diferença ontológica com as outras regiões brasileiras.

O Sul do Brasil seria o lugar dos resquícios incaicos; estaria embebido, nos tempos pré-históricos, pelas influências de uma "cultura superior". Afora o Sul, somente uma pequena ilha do Norte fora afortunada pelos contatos com os Incas, recebendo, por trocas comerciais, cerâmicas civilizadas. Haveria, por fim, marcas incaicas muito tênues, esmaecidas, apenas alguns machados de cobre encontráveis entre os Guaranis do território de São Paulo. O Sul do Brasil seria, pois, a única região a apresentar duradouras relações culturais com os "territórios vizinhos do Rio Prata, pelas quais se indicam influências de uma cultura superior procedida dos Andes", mais especificamente, proveniente, como já se disse, do Noroeste argentino (von Ihering, 1895, p.154-155). Porém, o Sul do Brasil encadear-se-ia, também, com a "cultura primitiva" das outras regiões do Sudeste brasileiro - o que, inevitavelmente, abriu-lhe os flancos para contatos culturais espúrios, que macularam a pureza original dos Guaranis, rebaixando-os (von Ihering, 1895, p.156).

O Diretor do Museu Paulista, pois, concebe os territórios arqueológicos do Brasil como heterogêneos. A influência cultural dos Incas, por meio dos contatos com os Guaranis, não se fez sentir por todo o litoral do Brasil; ainda que os Guaranis ocupassem

Anos 90, Porto Alegre, v. 12, n. 21/22, p.415-436, jan./dez. 2005 
todo o litoral, a área limite por onde se lançaram "círculos ondulatórios" de civilização foi o Sul do Brasil. As inúmeras diferenças entre as arqueologias do Rio Grande do Sul e São Paulo, por si mesmas, já demonstrariam que a difusão de uma "cultura superior" chegou ao Sul do Brasil e em toda a América do Sul, com exceção da Patagônia. E, assim, von Ihering descreve outros vestígios e documentos que provariam empiricamente a inserção de traços andinos numa porção do Brasil: os "machados perclusos" e de cobre, as chapinhas de prata encontradas em sambaquis do litoral gaúcho, as crônicas históricas que fazem menção ao uso de ouro e prata pelos Guaranis - tudo isso, para von Ihering, mostraria a concordância da tradição arqueológica com a histórica, formaria "uma base sólida para discutir a história primitiva da parte meridional do Brasil" (von Ihering, 1895, p.155).

Em seus outros textos arqueológicos e antropológicos, von Ihering pouco modificou essa "base sólida" sobre a Arqueologia do Sul do Brasil. Em A Etnologia do Brasil Meridional (1906), por exemplo, ele reproduz a mesma tese sobre a singularidade préhistórica do Sul do Brasil, arrolando a mesma diáspora de artefatos, que provaria antigas relações entre os Incas da região subandina da Argentina e os Guaranis. Para ele, haveria fatos de ordem arqueológica que

demonstram a influência que a cultura dos povos subandinos da Argentina exercia sobre o Brasil [...] Objetos de metal, particularmente chapinhas de prata e machados de cobre, foram também introduzidos da mesma região andina para o Paraguai e até no Brasil meridional (von Ihering, 1906, p.236).

Entre 1901 e 1904, o Museu Paulista recebeu por intercâmbio, angariou em expedições e comprou diversas coleções arqueológicas: a dos irmãos Berbedo, que foram objeto de um artigo, publicado por Paldaof (1900), bem como a de Karl Kosertiz, ambas 
Arqueologia do Sul do Brasil e política colonial em Hermann von Ihering

do Rio Grande do Sul; por fim, a enviada por Cristóvão Barreto, "arqueólogo amador" da região de Amargosa, na Bahia (von Ihering, 1904b; Rodolfo von Ihering, 1907). Essas coleções serviram à escrita de A Arqueologia Comparativa do Brasil (1904a). Nesse ensaio, contudo, também não há mudanças substanciais em suas teses acerca das relações dos Andes com a Ilha de Marajó e, principalmente, com o Sul do Brasil. Do mesmo modo, em A Antropologia do Estado de São Paulo (1907b), von Ihering, uma vez mais, reafirma sua tese, agora acrescendo à metáfora geométrica dos "círculos ondulatórios" uma metáfora geográfica, longitudinal:

Como já demonstrei, podemos provar no Estado do Rio Grande do Sul a existência de utensílios introduzidos pelos índios dos Pampas; encontram-se também outros instrumentos, que os índios do Rio Grande do Sul ganharam pelas suas relações com os Calchaquis e outras tribos de civilização mais adiantada, habitantes da região andina da Argentina, [e] a influência dos povos andinos é mais forte sobre os das regiões mais próximas desta zona e tanto mais enfraquece quanto maior a distância (von Thering, 1907b, p.246-247).

\section{Política colonial}

Vê-se, assim, como von Ihering, ao circunscrever territórios arqueológicos primitivos, delimitou identidades históricogeográficas. Delimitações que, a bem dizer, possuem significados políticos. Qualquer definição de identidade é sempre política. Os "valores etnológicos dos artefatos" findam sendo marcadores de regiões arqueológicas, indicadores de diásporas, índices de regionalidades culturais, de hegemonias dispersas no "continente brasileiro", porém isoladas em paredões naturais, paleontológicos e zoológicos, influenciadas por imigrações de artefatos que transcendem as raias geopolíticas. As determinações espaciais e políti-

Anos 90, Porto Alegre, v. 12, n. 21/22, p.415-436, jan./dez. 2005 
cas da epistemologia arqueológica de von Ihering revelam uma gramática da pertença. Os artefatos, como portadores de uma linguagem, expressam identidades sócio-cartográficas, são sinais a serem decompostos por uma hermenêutica, são a semiologia da cultura material, são os significantes dos significados regionais.

Uma gramática da pertença que funciona como um conjunto de regras responsáveis pela seleção de substantivações e adjetivações: culturas superiores e inferiores. Uma gramática da pertença que declina as conjugações psicossociais e os comporta-

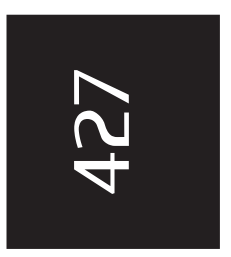
mentos culturais dos "bravos" e dos "mansos", dos civilizados e incivilizados, dos perfectíveis e imperfectíveis, cujos predicados anunciam sujeitos estigmatizados por estereótipos coloniais. Assim, von Ihering, no ensaio de 1895, descreve os índios Pampas da Argentina, índios que seriam culturalmente semelhantes aos Botocudos, os quais, de acordo com o naturalista, sempre mantiveram contato. Não se poderia compactuar politicamente com os Pampas. Afinal, já no Período Colonial, eles incendiavam navios e edifícios, apanhavam "com laço e flecha o veado de suas vastas planícies cujo sangue chupavam ainda quente, como até hoje fazem os índios do sul da República Argentina" (von Ihering, 1895, p.128).

Estereótipos coloniais, seguindo-se à defesa da guerra justa. O Diretor do Museu Paulista colecionava avidamente não só artefatos, mas também artigos de jornais que narravam os "assaltos" de índios aos sertanejos do Brasil. Os Botocudos e suas destruições em fazendas e cidades das "colônias alemãs" de Santa Catarina são freqüentemente citados por von Ihering; e, neste sentido, ele legitima a ação do Estado do Rio Grande do Sul que, ao descobrir "campos de bugre", declarou-lhes guerra (von Ihering, 1895, p.39). Vencida a guerra, nas palavras do Diretor, "os progressos da civilização não se interromperam mais no Rio Grande do Sul, enquanto que em Santa Catarina os Botocudos continuam a causar desastres" (von Ihering, 1895, 40). Longes da influência imediata do 
Arqueologia do Sul do Brasil e política colonial em Hermann von Ihering

"círculo andino", os Botocudos, de tão primitivos, só "possuem interesse etnológico bastante limitado" (von Ihering, 1895, p.46).

A tendência das interpretações arqueológicas de von Ihering foi a de formular, nessas "regiões transitórias", uma dicotomia básica: de um lado, os Guaranis que beberam das fontes incaicas; de outro, uma cultura primitiva, que teria originalmente habitado os sambaquis (von Ihering, 1903). A esses primitivos, von Ihering, em mais de um texto, uniformiza numa mesma etnia, ligando-a ao tronco lingüístico Jê (cf., por ex., von Ihering, 1904c, 1906). Etnia que sempre cometeu, conforme von Ihering afirma em $A$ Antropologia do Estado de São Paulo (1907b), uma série de crimes e assassinatos no vale do Paranapanema. O naturalista, nesse texto, faz a crônica desses "assaltos", que ocorriam, inclusive, no momento em que ele redigia o ensaio. E, após interpretar os dados antropológicos e arqueológicos do Estado de São Paulo, ele concluiu pela pobreza cultural dos "indígenas paulistas", o que lhe autorizou a sentenciar o extermínio dos Kaingangs que resistiam ao avanço dos cafeicultores do Oeste Paulista (von Ihering, 1907b, 215).

São bem conhecidos os debates ocasionados por essas declarações de von Ihering, relacionados com a criação, no interior do Museu Nacional e com o beneplácito do Governo Federal, do Serviço Nacional de Proteção ao Índio (SPI), no qual as correntes de pensamento positivista tiveram papel atuante (cf., por ex., Gagliardi, 1989; Lima, 1995). Não é o meu propósito, aqui, resenhar esses debates; mas deter-me naquilo que entendo ser a política colonial de von Ihering, arquitetada em A Questão dos Índios do Brasil (1911), texto escrito em resposta à criação do SPI e às críticas e diatribes que brotaram dos jornais cariocas e paulistas. Nesse texto, o naturalista afirma que o SPI, em sua inspiração positivista, não passa de uma sobrevivência anacrônica do romantismo, de uma "tupimania" e "filoindianismo epidêmico" (von Ihering, 1911, p.127). E assim ele articula, em contrapartida a essa epidemia tupi-maníaca, um programa de civilização composto por dez itens.

Anos 90, Porto Alegre, v. 12, n. 21/22, p.415-436, jan./dez. 2005 
Atenho-me ao último item, para mim o crucial, em que o Diretor do Museu Paulista compara o trabalho de educação dos indígenas aos empreendimentos coloniais da Europa. Como nas colônias européias, no Brasil seria necessário arregimentar técnicos e especialistas, lingüistas e antropólogos, bem como um corpo de funcionários auxiliares, treinados pelo Estado, que garantissem, a um só tempo, a cidadania brasileira aos "índios mansos" e a propriedade capitalista da terra (von Ihering, 1911, p.119). Sem alijar os missionários de sua empreitada colonial, que unicamente se incumbiriam do ministério da moral cristã, von Ihering, contudo, enfatiza que o problema fundamental dos indígenas é de educação, e não de catequese. Os funcionários do Estado, portanto, seriam majoritariamente amealhados entre cientistas e técnicos.

Assim, a civilização seria conduzida pelas mãos da Ciência, uma razão técnica, instrumental, detentora de um conhecimento especializado, implantada no aparelho de Estado. Neste sentido, von Thering sugere que o Governo organize expedições a fim de se colherem os materiais para a formulação de um saber científico sobre os indígenas:

É em Viena e na Alemanha que se encontram as coleções mais valiosas para o estudo da cultura indígena. No Brasil fizeram-se coleções de objetos reunidos ao acaso, que não tem a unidade e a minúcia daquelas coleções providas de todas as informações. Além das modestas expedições do Museu Paulista, não se realizou expedição alguma organizada pelo governo do Brasil, com a intenção de estudar o problema. Deverá servir de modelo ao Brasil o Ethnographical Bureau da América do Norte; tudo depende nesse caso da competência dos exploradores [...]. (von Ihering, 1911, p.134).

Hermann von Ihering, pois, pensa uma política colonial fundada na razão de Estado e na defesa da propriedade privada. Uma política colonial respaldada num saber técnico e científico que ele, 
Arqueologia do Sul do Brasil e política colonial em Hermann von Ihering

como Diretor do Museu Paulista, praticava. Em diversos relatórios administrativos, von Ihering gabou-se das coleções arqueológicas e etnográficas do Museu Paulista, coleções capazes de fazer frente àquelas dos Museus de Viena e da Alemanha, que ele, como se vê pela citação acima, tinha como preciosas. Em seu texto de política colonial ele voltou à carga, referendando, além disso, seu trabalho como cientista: "examinei e medi índios de várias tribos, e consegui reunir valiosa coleção antropológica e arqueológica no Museu Paulista. Frutificaram os meus esforços em grande número de publicações" (von Ihering, 1911, p.114).

É sintomático que von Ihering tenha invocado, como modelo de seu plano de colonização, justamente o Bureau of Ethnological Research, a instituição responsável, conforme lembra-nos Bruce G. Trigger (1990, p.125-126), pela elaboração e fundamentação antropológica das políticas colonialistas dos Estados Unidos. De sua parte, no interior do Museu Paulista von Ihering não somente aparelhou expedições arqueológicas e antropológicas, em fins de 1909 e 1910, para explorar grutas calcárias do Vale do Ribeira e contatar os últimos Xavantes (Hermann e Rodolfo von Ihering, 1911); mas também acionou a ciência humboldtiana, que sempre foi ativada na construção dos Impérios europeus (MacLeod, 2001), para confeccionar mapas de distribuição dos grupos indígenas do sul do Brasil. Um deles figurando os índios mortos, que viveram à época da colonização portuguesa, outro retratando os índios de carne e osso, que ainda viviam e "assaltavam" as fazendas de café.

Mapas que ele estampou em A Antropologia do Estado de São Paulo (von Ihering, 1907b) e reproduziu em $A$ Questão dos Indios no Brasil (1911), classificando-os como pertinentes às tarefas administrativas:

Organizei mapas indispensáveis sobre a distribuição dos campos e matas do Brasil, e sobre a distribuição geográfica dos índios na época da descoberta e na atualidade. Relativamente a este assunto não há porventura pessoa alguma 
com mais experiência do que eu, mas as questões aqui estudadas ultrapassam em parte a minha competência. Trata-se de assunto de caráter administrativo-social, nos quais evidentemente as questões divergem. (von Ihering, 1911, p.138).

Os mapas de von Ihering, não obstante as divergências administrativas que suscitariam, serviriam, de todo modo, para localizar os indígenas no espaço, aplainando o terreno, assim, para a efetivação de um colonialismo interno. Pois é exatamente um projeto de colonização interna o que von Ihering evoca. Conforme o conceituam vários pós-colonialistas (Loomba, 1998; Young, 2001; Brydon, 2000; Quayson, 2000), o colonialismo não é somente uma força política externa que acomete um povo e seu território, dominando-os e governando-os; ele pode ser também fabricado por elites locais, no interior mesmo de uma fronteira nacional, contanto que essa elite, empossada no Estado e em seus aparelhos, desencadeie e imagine projetos de colonização e de conquista dos "nativos" e de espaços geográficos, valendo-se dos aparatos do exército ou da ciência, e contanto que ela legitime cientificamente, como diz Theo Goldberg, uma hierarquia política interna baseada no governo racial (racial rule) (Goldberg, 1999). Nos termos de Gramsci, o colonialismo interno pode ser pensado como uma guerra de posições, uma tática para a dominação de classe, para a composição das forças sociais em prol da obtenção de uma hegemonia, uma guerra conduzida de forma lenta, contínua, envolvendo manobras diversas e variáveis.

A própria síntese arqueológica de von Ihering sobre o Sul do Brasil funciona como uma arma para as guerras de posição, é instrumento de defesa da hegemonia de uma elite e da propriedade privada. Ela estabelece um conhecimento positivo, um saber técnico, capaz de ajustar os mecanismos de um governo racial. Pode ser lida, ainda, como uma alegoria para o presente de São Paulo e do Brasil republicano - se no passado pré-histórico a proximidade

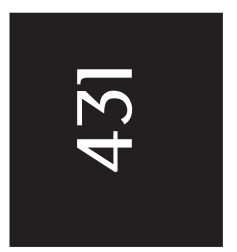


Arqueologia do Sul do Brasil e política colonial em Hermann von Ihering

com os "círculos ondulatórios" dos Andes civilizou os índios, no presente estes se civilizarão apenas se se aproximarem do patronato de cientistas, que laboram planos de colonização e fundam, como o fez von Ihering em 1901, instituições ocupadas com a Etnografia e Civilização dos Índios (von Ihering, 1911, p.122-123). Àqueles que estão distantes da civilização, aos que cometem "assaltos" e não possuem qualquer "interesse etnológico", cabe-lhes a política da força, a política de extermínio, que é, afinal de contas, também ela uma política colonial.

Estudar o pensamento arqueológico de von Ihering é, de algum modo, confrontar o nosso próprio pensamento. Pois, com efeito, afirma-se com freqüência que a Arqueologia não se livrou do passado colonial, que ele continua rondando como um espectro de Hamlet a cabeça dos arqueólogos e as relações sociais e políticas contemporâneas, neste mundo marcado pelos desequilíbrios e guerras globais e por hábitos de pensamento ainda aprisionados a estereótipos coloniais (Gosden, 2002). Representações coloniais ainda povoam, como afirma o arqueólogo sul-africano Martin Hall, as interpretações contemporâneas sobre a cultura material dos "países periféricos" (Hall, 2000). Conscientes dessas permanências hermenêuticas, no World Archaeological Congress, realizado em Washington, em junho de 2003, Chris Gosden, Richard Hingley e Pedro Paulo Abreu Funari organizaram uma sessão para discutir as relações entre colonialismo, Arqueologia e formação de identidades. Em se tratando de Brasil, pode-se assim dizer que as interpretações arqueológicas de von Ihering não são um resíduo arcaico, mas sim, para usar a bela expressão de Lynn Meskell (Meskell, 1998, p.4), um "artefato herdado" (inherited artifact). Fazer pesquisas arqueológicas no Brasil, historiográficas ou de campo, escavando textos ou sítios, é ainda tomar parte numa guerra de posições; numa sociedade desigual e em conflito como a nossa, a questão é escolhermos de qual lado ficaremos. 
Archeology of Southern Brazil and colonial politics in Hermann von Ihering Abstract. This paper aims at analyzing the archaeological studies by of the Hermann von Ihering as a constitutive element of the colonial policy building.

Keywords: Archaeology. Paulista Museum. South of Brazil. Colonial policy.

\section{Notas}

${ }^{1}$ Este texto foi escrito para ser apresentado no IV Encontro do Núcleo Regional da Sociedade de Arqueologia Brasileira (SAB), ocorrido em Criciúma (SC), entre 8 e 12 de novembro de 2004. As discussões suscitadas durante a apresentação levaram-me a redigi-lo em alguns de seus pontos. Agradeço, pois, aos colegas pelos estimulantes questionamentos. Agradeço também a Pedro Paulo Abreu Funari e a Francisco Noelli pelas críticas à versão original; devo agradecer, ainda, a professora Margaret Lopes, pelas conversas que tivemos sobre von Ihering, sem as quais seria muito mais difícil compreender os textos do Diretor do Museu Paulista. Por fim, meus agradecimentos à FAPESP, que apóia minhas pesquisas desde o Mestrado. A responsabilidade pelas idéias é minha. O texto é dedicado a Silvana e a André, amigos de todas as horas.

\section{Referências}

BROWNE, J. Biogeography and Empire. In: JARDINE, N.; SECORD, J. A.; SPARY, E. C. Cultures of Natural History. Cambridge: Cambridge U. P., 1997. p. 305-321.

BRYDON, D. (Ed.). Internal colonialisms and subaltern studies. In: Postcolonialism; critical concepts in literary and cultural studies. London: Routledge, 2000. V. IV, p. 1345-1568.

CHAMBERLAIN, A. F. The Allentiacan, Bororoan and Calchaquian linguistic stocks of South America. American Anthropologist, v.14, n. 3, p.499-507, 1912.

DETTELBACH, M. Humboldtian science. In: JARDINE, N.; SECORD, J. A.; SPARY, E. C. Cultures of Natural History. Cambridge: Cambridge U. P. 1997. p. 287-304.

GAGLIARDI, J. M. O indígena e a República. São Paulo: Hucitec; Edusp, 1989.

GINZBURG, C. Mitos, emblemas e sinais; morfologia e história. São Paulo:

Companhia das Letras, 1989.

Anos 90, Porto Alegre, v. 12, n. 21/22, p.415-436, jan./dez. 2005 
Arqueologia do Sul do Brasil e política colonial em Hermann von Ihering

GOLDBERG, T. G. The racial rule. In: GOLDBERG, D. T.; QUAYSON, A. Relocating postcolonialism. Oxford: Blackwell Publishing, 1999. p. 82-102.

GOSDEN, C. Anthropology and Archaeology. London: Routledge, 2002.

HALL, M. Archaeology and modern world; colonial transcripts in South Africa and the Chesapeake. London: Routledge, 2000.

HARTT, C. F. Descrição dos objetos de pedra de origem indígena conservados no Museu Nacional. Arquivos do Musen Nacional, n.1, p. 45-53, 1876 a.

Notas sobre algumas tangas de barro cosido dos antigos indígenas da ilha de Marajó. Arquivos do Museu Nacional, n.1, p. 21-25, $1876 \mathrm{~b}$.

HASEMAN, J. D. Some notes on the Pawumwa Indians of South America. American Anthropologist, v.14, n. 2, p.333-349, 1912.

IHERING, H. von. A civilização pré-histórica no Brasil Meridional. Revista do Мияеи Paulista, n.1, p. 33-159, 1895.

Os moluscos dos terrenos terciários da Patagônia. Revista do Museu Paulista, n.2, p. 73-114, 1897.

1898.

O Museu Paulista no ano de 1897. Revista do Миseu Paulista, n.3, p. 9-16,

. A origem dos sambaquis. RIHGSP, n.8, p. 446-457, 1903. 580,1904a

Arqueologia comparativa do Brasil. Revista do Museu Paulista, n. 6, p.519$1904 b$.

O Museu Paulista em 1901 e 1902. Revista do Musen Paulista, n. 6, p.1-22,

Os Guaianáses e Caingangues do estado de São Paulo. Revista do Museu Paulista, n. 6, p.23-44, 1904c.

Resíduos da Idade da Pedra na cultura atual do Brasil. RIHGSP, n. 9, p. 570-575, 1905.

A Etnologia do Brasil Meridional. RIHGSP, n. 11, p.220-236, 1906.

Os índios Patos e o nome da Lagoa dos Patos. Revista do Museu Paulista, n. 7, p.31-45, 1907a.

A Antropologia do estado de São Paulo. Revista do Museu Paulista, n. 7, p. $202-257,1907 b$.

Anos 90, Porto Alegre, v. 12, n. 21/22, p.415-436, jan./dez. 2005 


\section{Lúcio Menezes Ferreira}

IHERING, H. von. Os machados de pedra dos índios do Brasil e o seu emprego nas derrubadas de mato. RIHGSP, n. 12, p. 426-431, 1907c. $140,1911$.

A questão dos índios do Brasil. Revista do Museu Paulista, n. 8, p.122-

IHERING, Hermann; IHERING, Rodolfo. O Museu Paulista entre os anos de 1906 e 1909. Revista do Musen Paulista, n. 8, p.1-22, 1911.

IHERING, Rodolfo von. O Museu Paulista nos anos de 1903 e 1905. Revista do Миsеu Paulista, n. 7, p.5-30, 1907.

LA HURE, Conde de. Consideratións sommaires sur l'origene des amas de coquillages de la Côte du Brésil. Dona Francisca (SC), 10.02.1865. IHGB, lata 15, pasta 9, 1865. Manuscrito.

LIMA, A. C. de S. Um grande cerco de paź, poder tutelar, indianidade e formação do Estado no Brasil. Petrópolis: Vozes, 1995.

LOOMBA, A. Postcolonialism. London: Routledge, 1998.

LOPES, M. Margaret. O Brasil descobre a pesquisa científica; os museus e as ciências naturais no século XIX. São Paulo: Hucitec, 1997.

LOSANO, M. G. Hermann von Ihering: um precursor da Ecologia no Brasil. Revista da USP, n. 13, p.88-99, 1992.

MAcLEOD, R. (Ed.). Nature and empire; science and the colonial enterprise. Chicago: University of Chicago Press, 2001.

MESKELL, L. (Ed.). Archaeology under fire; nationalism, politics and heritage in the Eastern Mediterranean and Middle Eastern. London: Routledge, 1998.

NETO, Ladislau. Carta a Charles Wiener. Arquivos do Museu Nacional, n. 1, p.1-2, 1876.

Investigações sobre a Arqueologia Brasileira. Arquivos do Museu Nacional, n. 6, p.257-553. 1885.

PALDAOF, J. M. Arqueologia rio-grandense. Revista do Museu Paulista, n. 4, p.339-349, 1900.

QUAYSON, A. Postcolonialism: theory, practice or process? Oxford: Oxford U. P., 2000.

RUDWICK, M. Georges Cuvier's paper museum of fossil bones. Archives of Natural History, v. 27, n.1, p.51-68, 2000. 
Arqueologia do Sul do Brasil e política colonial em Hermann von Ihering

SAVILLE, M. H. Precolumbian decoration of the teeth in Ecuador. With some Account of the occurrence of the custom in other parts of North and South America. American Anthropologist, v. 15, n.3, p.377-394, 1913.

SHENNAN, S. Population, culture history, and dynamics of culture change. Current Anthropology, v. 41, n.5, p.2-34, 2000.

TRIGGER, B. G. A bistory of archaeological thought. Cambridge: Cambridge U. P., 1990.

WIENER, C. Estudos sobre os sambaquis do Sul do Brasil. Arquivos do Musen Nacional, n. 1, p.3-20, 1876.

YOUNG, R. Postcolonialism; a historical introduction. Oxford: Blackwell Publishing, 2001.

Recebido em 03/12/2004.

Aprovado em 22/06/2005.

Anos 90, Porto Alegre, v. 12, n. 21/22, p.415-436, jan./dez. 2005 